\title{
AFM Study on Surface Microtopography, Morphology and Crystal Growth of Hydrothermal Illite in Izumiyama Pottery Stone from Arita, Saga Prefecture, Japan
}

\author{
Yoshihiro Kuwahara $^{1, *}$ and Seiichiro Uehara ${ }^{2}$
}

\author{
${ }^{I}$ Department of Evolution of Earth Environments, Graduate School of Social and Cultural Studies, Kyushu University, \\ Ropponmatsu, Fukuoka 810-8560, Japan and ${ }^{2}$ Department of Earth and Planetary Sciences, Faculty of Science, Kyushu \\ University, Fukuoka 812-8581, Japan
}

\begin{abstract}
Atomic force microscope (AFM) observation and analysis of Izumiyama hydrothermal illite (the weaker altered illite-kaolinite zone (IZ-1) and the higher altered illite zone (IZ-2)) were performed to understand the crystal growth mechanism and the relation between morphology and polytype of the illites. Our AFM results suggest that growth of the Izumiyama illite was controlled by a mechanism of solution-mediated polytype and spiral-type transformations, based on the Ostwald ripening process. The sequential variations could follow the changes in supersaturation and/or temperature of the solution. The paths of the thermal and supersaturation condition changes of the hydrothermal solutions for the two samples were estimated from the saturation state of the solution, which was evaluated by the step separation, polytype and mineral assemblage of the samples.
\end{abstract}

Key Words: Atomic force microscopy (AFM), hydrothermal illite, crystal growth, spiral pattern, polytype.

\section{INTRODUCTION}

After Frank [1] suggested the spiral growth mechanism to account for the growth of vapor-phase crystals, growth spirals with unit-cell-order step heights were observed on many mineral surfaces mainly by the following two methods, phase-contrast and interference contrast microscopy [24] and the platinum-carbon (PT-C) replica and golddecoration methods for transmission electron microscopy (TEM) [5-11]. These methods, however, do not permit to quantify surface microtopography on the unit-cell-order of minerals. Phase-contrast and interference contrast microscopy are sensitive to vertical resolution, but the lateral resolution is limited to that of optical microscopy [6]. In the PT$\mathrm{C}$ replica and gold-decoration methods, the thickness of a sample is primarily estimated from the length of its shadow cast at a low angle in PT-shadowed TEM specimen [12]. The resolution of thickness measurement of the shadowed specimen is $\pm 4 \AA$ at a shadowing angle of $10^{\circ}$, making it difficult to determine whether the thickness is within $10 \AA$ or $7 \AA$, i.e. a 2:1 or 1:1 phyllosilicate layer [12-14].

This problem has largely been overcome by atomic force microscopy (AFM). It is a promising tool for quantifying surface microtopography on the order of the unit-cell of minerals. The use of AFM for ultrafine particles such as clay minerals permits morphological measurement of high accuracy, including particle dimension, step height, and step separation, that cannot be performed by other techniques [12, 14-18].

*Address correspondence to this author at the Department of Evolution of Earth Environments, Graduate School of Social and Cultural Studies, Kyushu University, Ropponmatsu, Fukuoka 810-8560, Japan;

E-mail: ykuwa@scs.kyushu-u.ac.jp
It is well known that illite and kaolin minerals formed under hydrothermal condition show spiral growth pattern on their (001) crystal surfaces, produced by the spiral growth mechanism $[6,7,9,17,18]$. The morphology of growth spirals of illite or micas can potentially yield information on the solution saturation state during crystal growth. Kitagawa [9] and Kuwahara et al. [18] showed that the spiral shape and step separation of hydrothermal illite crystals depend strongly on the supersaturation condition of the solution. The morphology of growth patterns is also closely related to the occurrence (fissure filling, metasomatic, and massive metasomatic) and aggregation texture of crystals (higher and lower porosities in specimen) [9].

Izumiyama pottery stone deposit, located in the Saga prefecture of southwestern Japan, is a deposit discovered first in Japan in 1616 and thereafter has been used as materials of the Arita ware making until the Edo era [19]. The deposit was formed by hydrothermal alteration of a rhyolite intrusion and can be divided into four zones from the center to the outer of the alteration area (Fig. 1) [19]. In the deposit, hydrothermal illite is included mainly in the illite zone with illite veins (fissure filling or higher porosity) and the illitekaolinite zone (lower porosity) that produced high quality clay for the Arita ware $[19,20]$. Therefore, the deposit provides the opportunity to understand the formation process and mechanism of hydrothermal illite and the difference between the two types. It has been revealed by XRD, TEM and AFM studies that the hydrothermal illite in the two zones has the different structural and morphological characteristics [17-20]. However, the formation process and mechanism of the hydrothermal illite and the difference between the two have not been understood. On the other hand, in Izumiyama pottery stone, many lath-shaped hydrothermal illite particles 


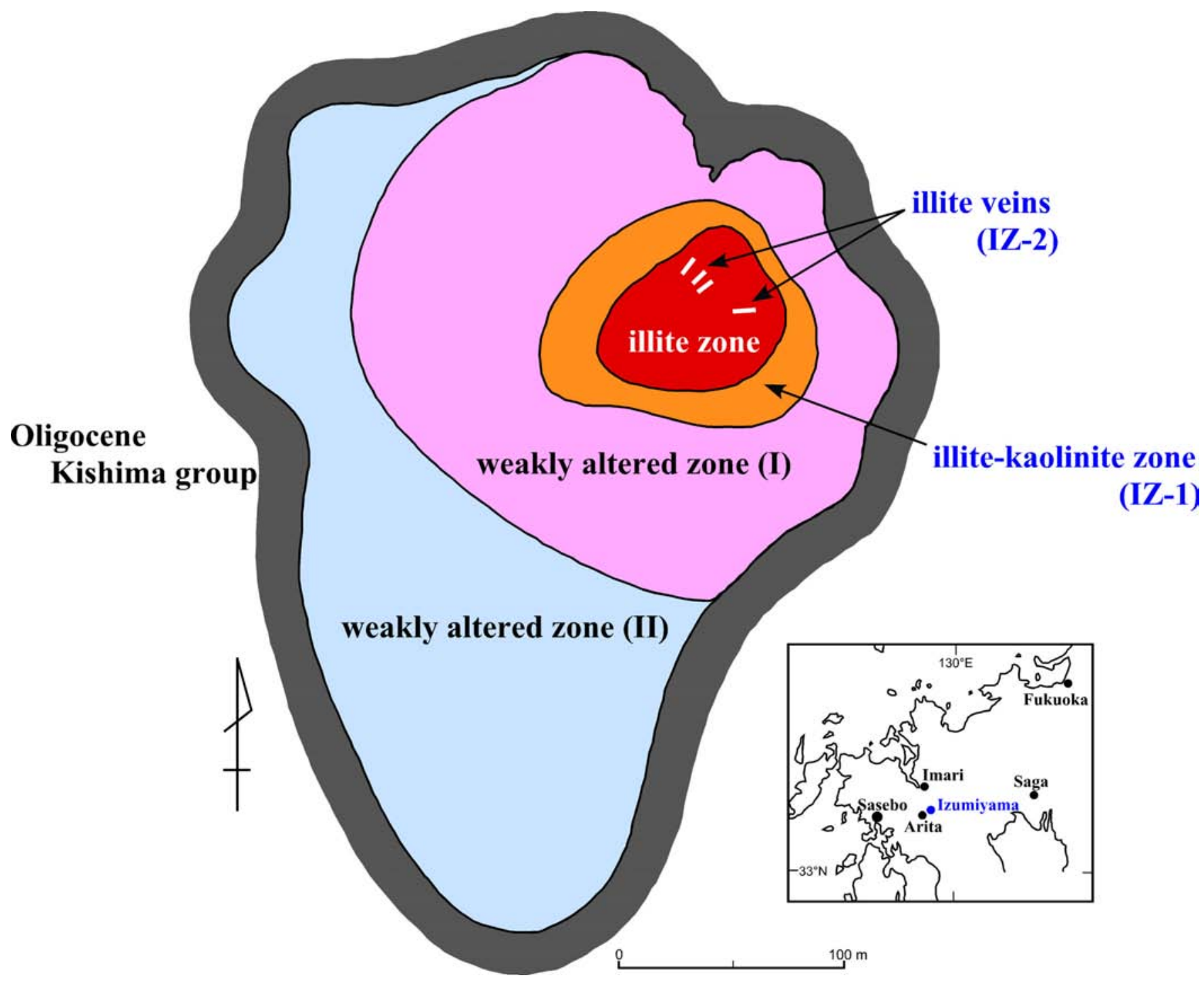

Fig. (1). Alteration zones of the Izumiyama pottery stone deposit. (after Nakagawa et al. [19]).

with $2 M_{1}$ polytype have been found by recent AFM study [18]. This is inconsistent with a previous conclusion regarding the shapes of $1 M$ laths and $2 M_{1}$ platelets of hydrothermal illite and synthetic mica based on TEM and powder X-ray diffraction (XRD) studies [21-23].

In this study, we performed the surface microtopographic observations and analyses of Izumiyama hydrothermal illite particles in the two hydrothermal alteration zones by AFM, to obtain the understanding of the spiral growth and polytype-transformation mechanisms. The comparison in morphological characteristics between the two hydrothermal illites demonstrates that they grew under different supersaturation conditions and different temperatures.

\section{EXPERIMENTAL}

\section{Materials}

Two ore samples (IZ-1, IZ-2) from the Izumiyama pottery stone deposit, Arita, Saga prefecture, Japan, were examined in this study. Sample IZ-1 is a white massive ore col- lected from the outer, weaker altered illite-kaolinite zone (Fig. 1) [19]. It contains illite with $1 M, 1 M d, 2 M_{1}$ and $2 M_{2}$ polytypes, kaolinite, K-feldspar and quartz, based on XRD and TEM [20]. Sample IZ-2 is a white clayey ore from illite veins of the inner, higher altered illite zone (Fig. 1) [19], and is consisted of nearly pure illite, with a mixture of $1 M, 2 M_{1}$ and $2 M_{2}$ polytypes, based on XRD and TEM [20] or a mixture of $1 M, 2 M_{1}$, and $2 O$ polytypes, based on AFM [18]. Our previous scanning electron microscopy (SEM), XRD and AFM studies of the samples showed that the illite particles are concentrated in the $<5 \mu \mathrm{m}$ fraction $[18,20]$. The age and temperature of hydrothermal alteration related to the formation of the Izumiyama pottery stone deposit have been estimated at 2.2-2.1 Ma and $\sim 250^{\circ} \mathrm{C}$, respectively [20, 24].

\section{AFM Imaging}

The sample preparation method used for AFM observations has been described by Kuwahara et al. [17]. Briefly, a dilute suspension of illite with distilled water was evaporated on a $\mathrm{Si}$ wafer, which is flat at the subnanometer scale. The 
AFM used was a Nanoscope III with a Multimode SPM unit (Digital Instruments). The samples were scanned in air in tapping-mode AFM (TMAFM), using a J-head piezoelectric scanner $(125 \mu \mathrm{m} X Y$ scans and $5 \mu \mathrm{m} Z$ scan $)$ and $125 \mu \mathrm{m}$ microfabricated Si cantilevers. The scanner was calibrated to both the Au-coated proof standard for the $X$ and $Y$ directions $(1 \mu \mathrm{m})$ and the Pt-coated crosshatched standard for the $Z$ direction $(150 \mathrm{~nm})$. In addition, the $c$ unit-cell height, measured using a phlogopite mica standard sample, was $1.0 \pm$ $0.08 \mathrm{~nm}$. The scanning rate was $1.0 \mathrm{~Hz}$. Setpoint voltage and
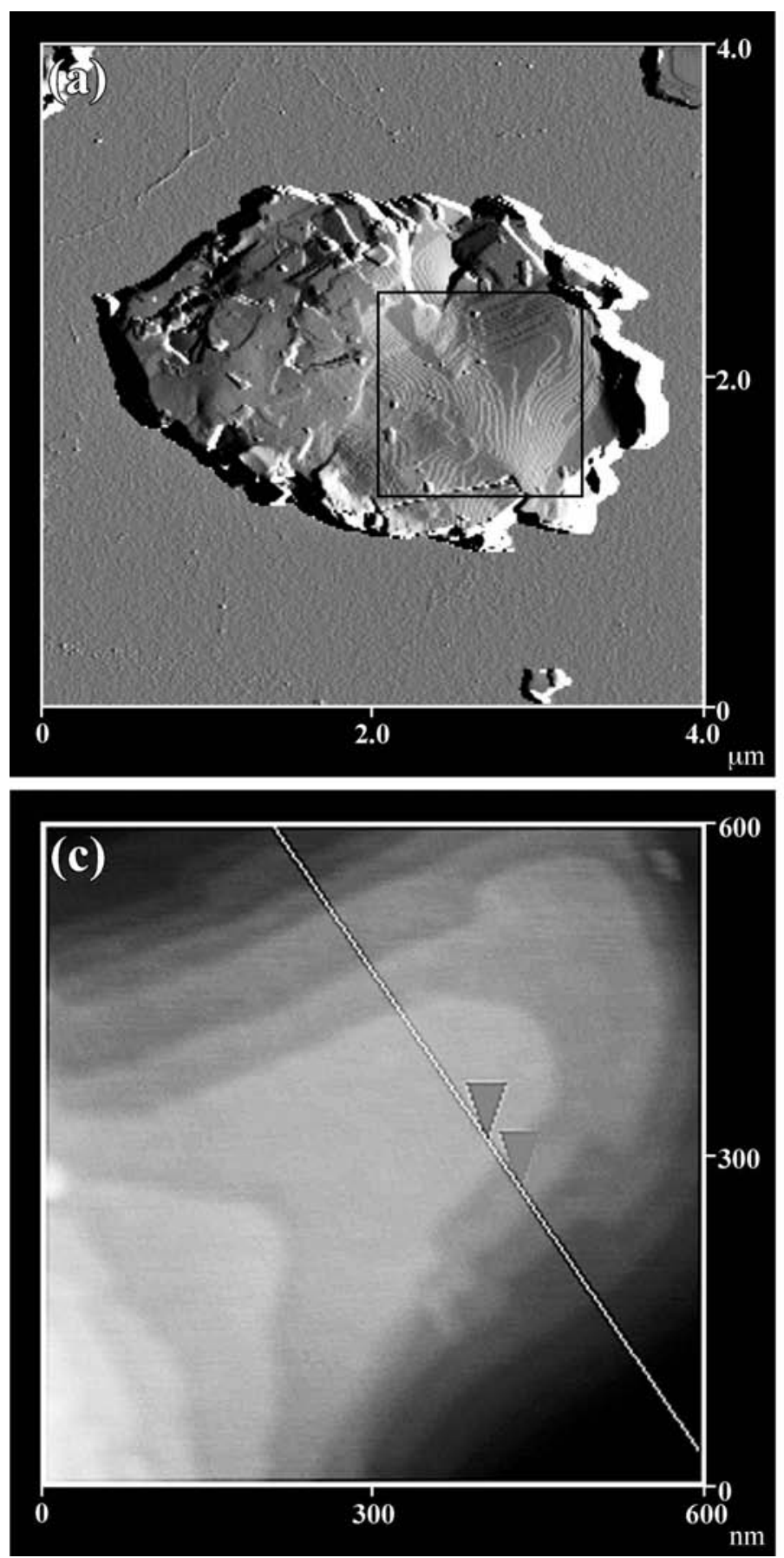

integral and proportional gain were adjusted for each scan accordingly.

We collected parallel height and amplitude images. The TMAFM height image is digitally recorded surface topography. The TMAFM amplitude image is essentially a record of the error in the height image under a constant force mode and amplifies the stepped appearance on the surface. The AFM image analysis, including the measurement of particle dimension, step height, and step separation, was performed using Nanoscope software (Veeco) and image SXM analysis
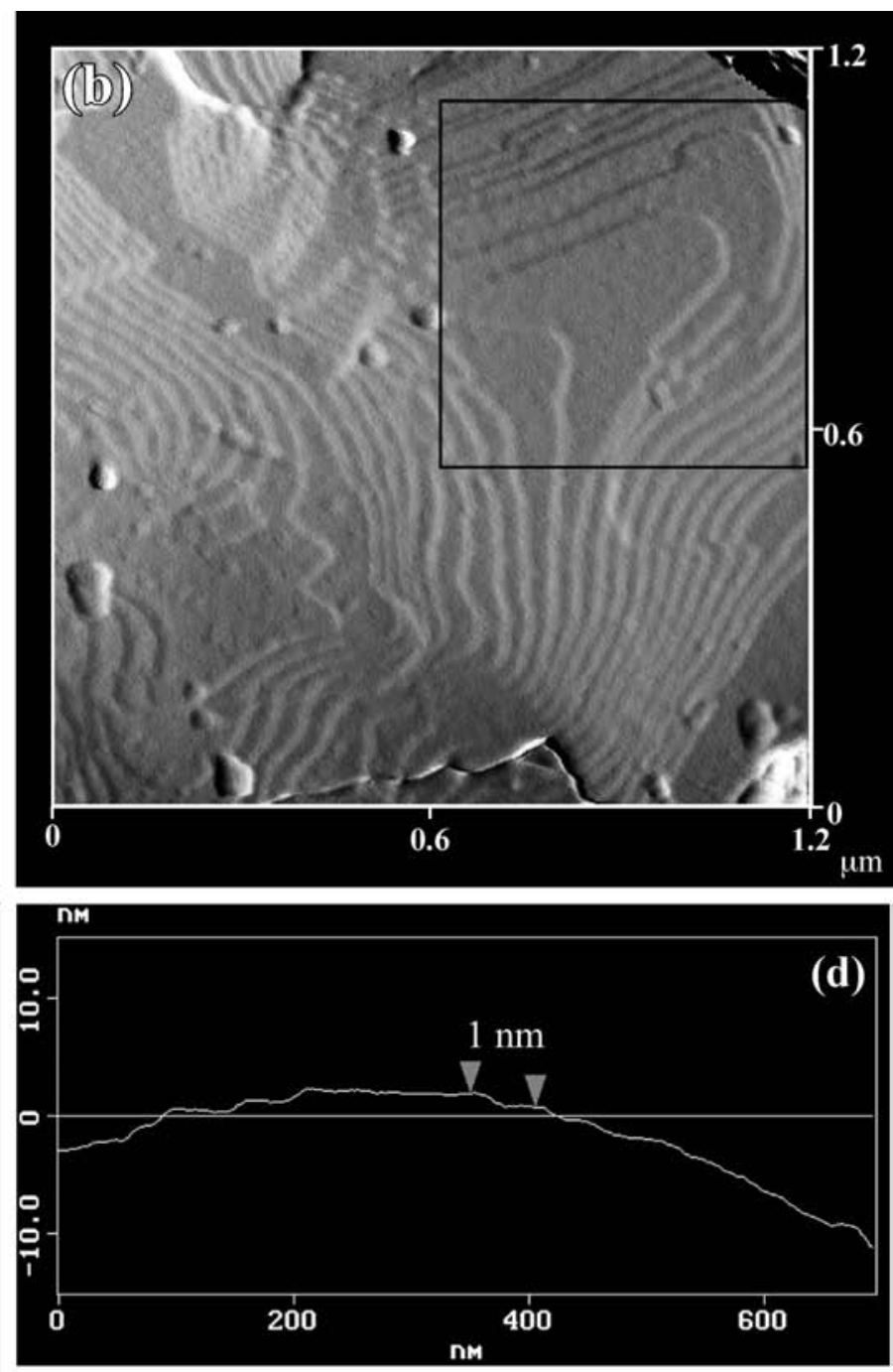

Fig. (2). (a) TMAFM amplitude image of a malformed illite particle showing circular step spirals (IZ-1). (b) Magnified view within the box in (a). (c) TMAFM height image enlarged within the box in (b). $Z=30 \mathrm{~nm}$. (d) A cross-sectional view along the white line in (c). Each step has a height of $1.0 \mathrm{~nm}$ corresponding to the thickness of a single unit-cell layer of mica. 

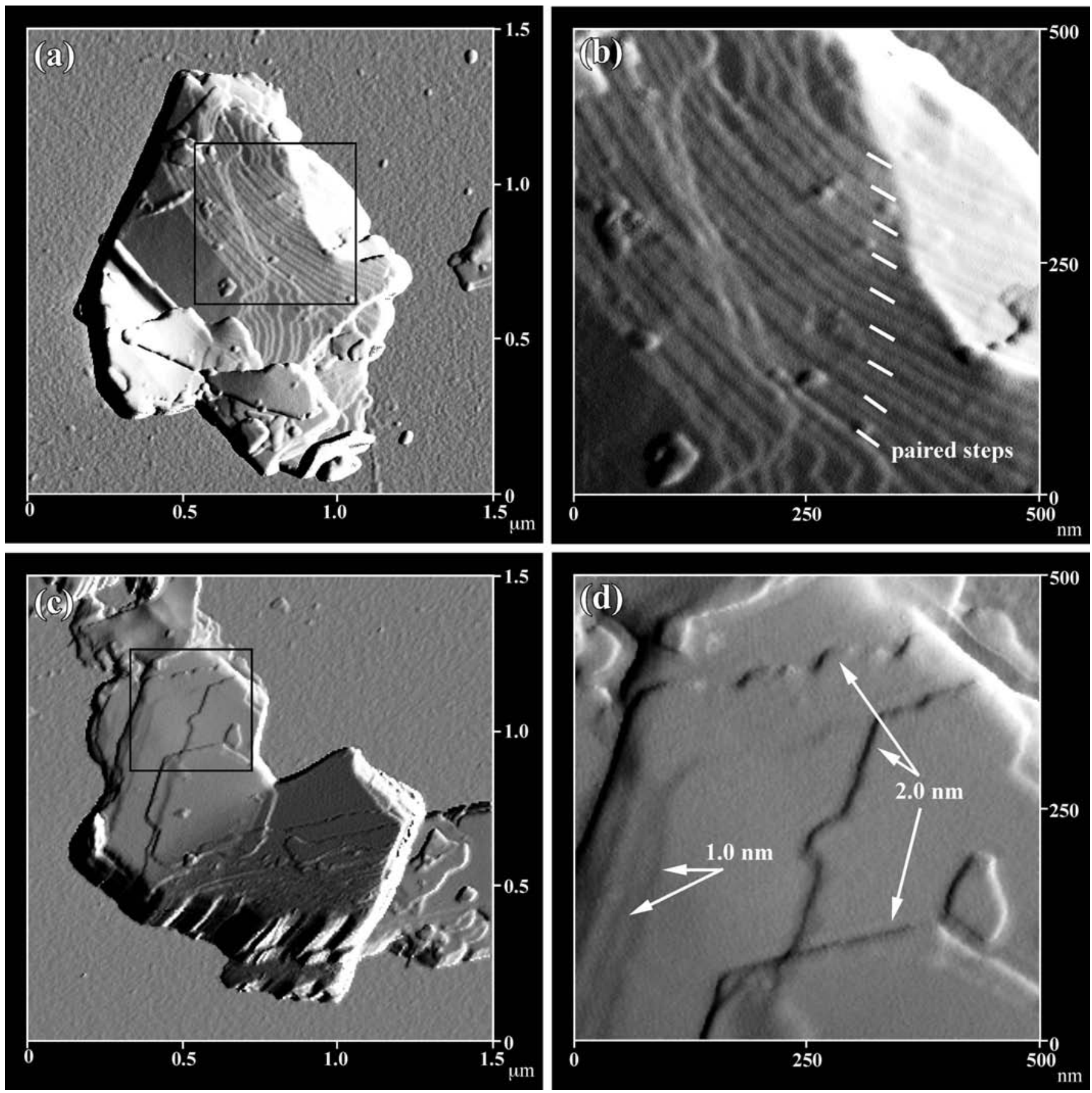

Fig. (3). (a) TMAFM amplitude image of a malformed illite particle having circular paired step spirals (IZ-1). (b) Magnified view within the box in (a). Each step has a height of $1.0 \mathrm{~nm}$ corresponding to the thickness of a single unit-cell layer of mica. (c) TMAFM amplitude image of a polygonal platy illite particle showing interlacing patterns on the (001) surface (IZ-1). (d) Magnified view within the box in (c). Step height is $1.0 \mathrm{~nm}$ corresponding to the thickness of a single unit-cell layer of mica or $2.0 \mathrm{~nm}$ to the thickness of two single unit-cell layers.

program [25]. The error of the analysis is estimated to be less than $5 \%[17,26]$.

\section{RESULTS}

Izumiyama hydrothermal illite particles exhibited platy to lath shapes (Figs. 2-4). The individual platy particles were circular, malformed circular, rectangular, hexagonal and other polygonal shapes. Lath-shaped particles had commonly euhedral or straight terminations. Coalesced particles as well as single crystals were also found in some instances.
Many of the Izumiyama illite particles exhibited various growth spiral patterns or successive steps on their (001) surfaces (Figs. 2-4). Tables 1 and 2 show the morphological data of the illite particles with such spiral patterns in the samples IZ-1 and IZ-2, respectively. The particle shape seems to be related to the spiral shape. The circular or malformed crystals are characterized by circular spiral pattern, while the polygonal or lath-shaped particles exhibit polygonal spiral, in both the samples. However, the mean particle dimension and step separation tend to be larger in the sample 

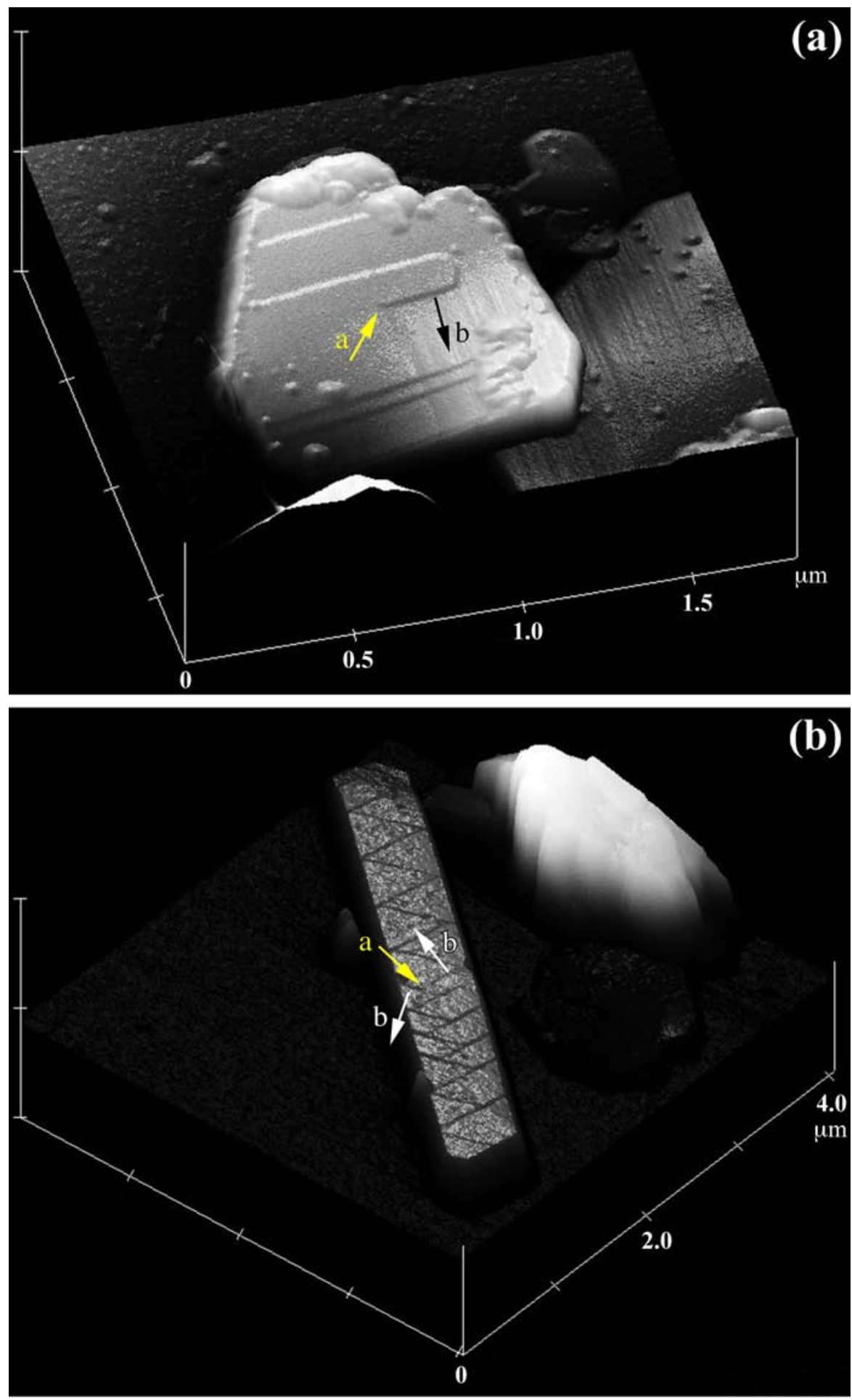

Fig. (4). (a) TMAFM height image of a polygonal platy illite particle showing polygonal single unit-cell layer spiral patterns on the (001) surface (IZ-2), $Z=100 \mathrm{~nm}$. Each step has a height of $1.0 \mathrm{~nm}$. Yellow allow (a) indicates a single screw dislocation point generating a single unit-cell layer and white allow (b) indicates the spiral direction. (b) TMAFM height image of a lath-shaped illite particle showing interlacing patterns on the (001) surface (IZ-2), Z =300nm. Step height is $1.0 \mathrm{~nm}$ within the zigzag parts and $2.0 \mathrm{~nm}$ in the parallel parts. Yellow allow (a) indicates a single screw dislocation point generating a $120^{\circ}$ rotation of two single unit-cell layers and two white allows (b) indicate the two spiral directions.

IZ-2 than those in the IZ-1, especially in the polygonal and lath-shaped particles. In addition, in the IZ-1 the frequency of the circular and malformed particles was $>50 \%$, whereas in the IZ-2 that of the polygonal and lath-shaped particles was $>80 \%$.
Many of the circular and malformed particles in the IZ-1 and all of those in the IZ-2 showed a single unit-cell layer circular spiral on their (001) surfaces (Tables 1 and 2). The step height was $1.0 \mathrm{~nm}$, in consistent with the thickness of a 2:1 layer of mica (Fig. 2). Illite particles with such circular 
Table 1. Morphology, Spiral Shape, Polytype and Dimension of Izumiyama Hydrothermal Illite and Kaolinite Particles in the Sample IZ-1 $(\mathbf{N}=82)$

\begin{tabular}{|c|c|c|c|c|c|c|c|}
\hline Morphology & Spiral Shape & Polytype & $\begin{array}{c}\text { Frequency } \\
(\%)\end{array}$ & $\begin{array}{l}\text { Length } \\
(\mu \mathrm{m})\end{array}$ & $\begin{array}{l}\text { Width } \\
(\mu \mathrm{m})\end{array}$ & $\begin{array}{l}\text { Thickness } \\
\text { (nm) }\end{array}$ & $\begin{array}{c}\text { Step Separation } \\
(\mathbf{n m})\end{array}$ \\
\hline \multirow{2}{*}{$\begin{array}{l}\text { circular or } \\
\text { malformed platy }\end{array}$} & \multirow{2}{*}{$\begin{array}{l}\text { circular or mal- } \\
\text { formed circular }\end{array}$} & $1 M$ & 44 & $0.56-3.28(1.65)^{*}$ & $0.31-2.45(1.11)$ & 20-163(69) & $22-158(72)$ \\
\hline & & $2 M$ & 12 & $0.63-3.03(1.56)$ & $0.57-2.15(1.06)$ & $34-229(88)$ & $20-259(100)$ \\
\hline polygonal platy & polygonal & $1 M$ & 11 & $1.22-2.23(1.82)$ & $0.42-2.02(1.23)$ & $26-140(83)$ & 63-274(112) \\
\hline lath-shaped & $\begin{array}{c}\text { polygonal } \\
\text { (rarely malformed) }\end{array}$ & $\begin{array}{c}2 M \\
(1 M ?)\end{array}$ & 7 & $1.51-2.67(1.94)$ & $0.23-0.66(0.42)$ & $36-145(65)$ & $62-158(122)$ \\
\hline $\begin{array}{c}\text { kaolinite } \\
\text { (polygonal platy) }\end{array}$ & polygonal & & 14 & $0.77-3.10(1.77)$ & $0.34-2.34(1.25)$ & $39-545(249)$ & $34-173(82)$ \\
\hline
\end{tabular}

* Values in parentheses are the mean value.

Table 2. Morphology, Spiral Shape, Polytype and Dimension of Izumiyama Hydrothermal Illite Particles in the Sample IZ-2 $(\mathrm{N}=$ 60) (After Kuwahara et al. [18])

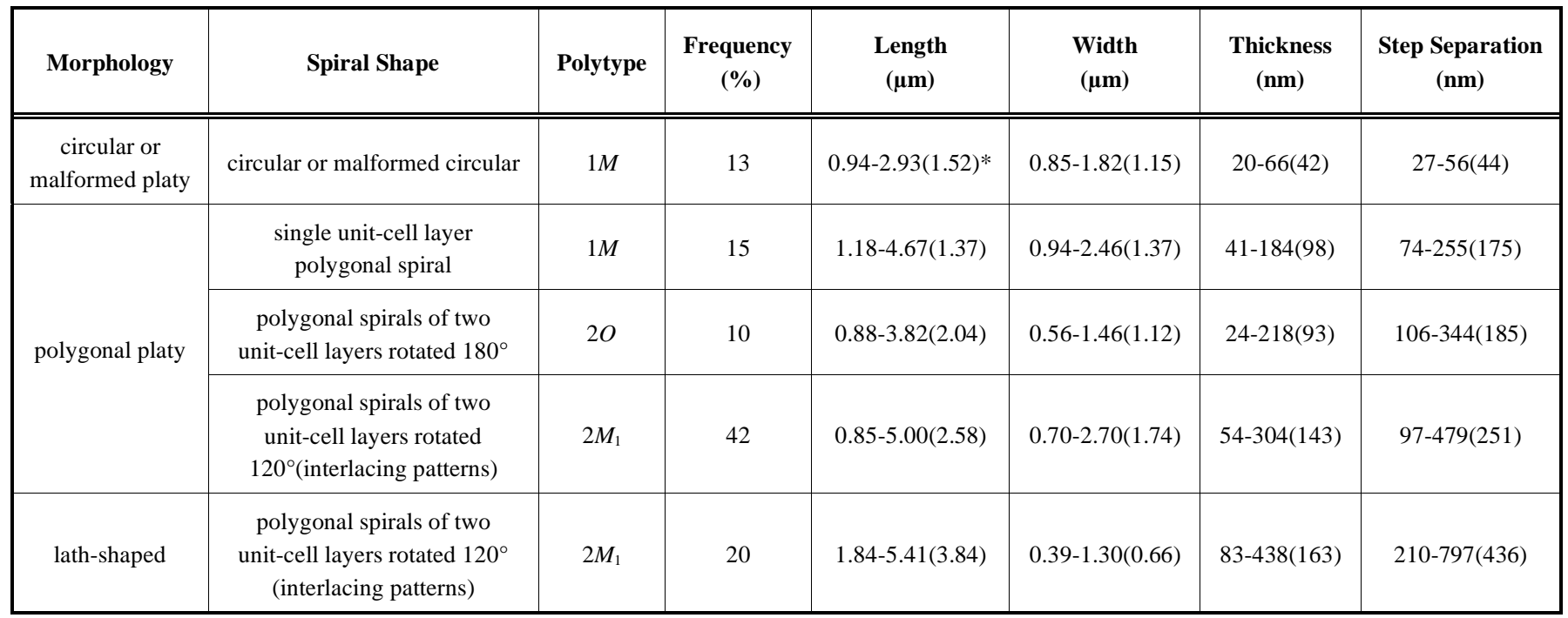

* Numbers in parentheses are the mean value.

spiral pattern were believed to be of $1 M$ polytype [18]. In the IZ-1, malformed crystals having circular, paired step spiral were found (Figs. $3 \mathbf{a}$ and $\mathbf{b}$ ), which could be the $2 M$ polytype [9]. The mean particle dimension and mean step separation of illite particles with circular spiral pattern were the smallest and narrowest, respectively, in all the types (Tables 1 and 2).

Three types of the polygonal spiral patterns were observed on the (001) surfaces of the polygonal platy particles (see Fig. 2 in Kuwahara et al. [18]). The first is a single unitcell layer polygonal spiral arising from a single screw dislocation point on the surface of a polygonal platy particle (Fig. 4a) [18]. The step height is $1.0 \mathrm{~nm}$, and thus this illite particle is the $1 M$ polytype $[10,18]$. The second type is the interlacing pattern formed by two single unit-cell layers rotated by $120^{\circ}$, originating from a single screw dislocation point on the particle surface (Figs 3c, d and 4b) [18]. The step heights are $2.0 \mathrm{~nm}$ in the parallel parts where the front of advancing step with a single unit-cell height overtakes that of the adjacent lower step and $1.0 \mathrm{~nm}$ in the zigzag parts where the one step does not overtake the adjacent lower step, respectively. This evidence confirms that the illite particle is the $2 M_{1}$ polytype $[6,17,18]$. Generally, the mean particle thickness and mean step separation of the polygonal platy illite $2 M_{1}$ particles are larger and wider than those of other platy particles in the samples. The third type, found only in the IZ-2, is parallel spiral patterns formed by two single unit-cell layers rotated by $180^{\circ}$, originating from a single screw dislocation point on the particle surface [18]. Each step has a height of $1.0 \mathrm{~nm}$, but this particle exhibits paired step patterns. The illite particle with such step spirals was first discovered by Kuwahara et al. [18], and is the $2 O$ polytype. The frequency of $2 O$ illite particles in the IZ-2 is up to $10 \%$ (Table 2 ), although the $2 O$ polytype is quite uncommon in illite or muscovite $[27,28]$. The mean particle thickness and mean step 
separation of the $2 O$ illite particles were nearly equal to those of the polygonal platy $1 M$ illite particles.

Many of the lath-shaped particles exhibited interlacing patterns, which are identical to the second type of the polygonal spirals showing on the surfaces of polygonal platy particles, as mentioned above (Fig. 4b). These lath-shaped particles, therefore, are the $2 M_{1}$ polytype. In general, the mean step separation of the $2 M_{1}$ lath-shaped particles is relatively wide.

\section{DISCUSSION}

\section{Growth Habit and Illite Polytype Dependence}

A strong dependence of the growth habit on the polytype of mica, i.e. $1 M$ laths and $2 M_{1}$ platelets, has been suggested by previous XRD and TEM studies of hydrothermal illites and synthetic micas [21-23]. Inoue et al. [23] showed that the growth of illite during smectite-to-illite conversion in the hydrothermal setting consists of two distinct growth sequences. The first stage is the growth of lath-shaped particles present in illite-smectite (I-S) with 55-20\% expandable layers, continuing metastably up to $0 \%$ expandable layers. The second stage is the growth of hexagonal particles in I-S with 20-0\% expandable layers. The first stage corresponds to the evolution from the $1 M_{d}$ to $1 M$ illite, while the second stage corresponds to the evolution of the $2 M_{1}$ illite.

In contrast, our AFM study on Izumiyama hydrothermal illites revealed that hexagonal or other polygonal platy particles have not only the $2 \mathrm{M}$ polytype but also the $1 \mathrm{M}$ or $2 \mathrm{O}$ polytype, and many of the lath-shaped ones are the $2 M$ polytype and the $1 M$ or $2 O$ platy particles occur frequently in the samples (Table 2). Therefore, there may be no correlation between the growth habit and the polytype of illite. As discussed below, this inconsistency between the previous XRD and TEM and our AFM studies may be caused by a crystal growth mechanism, based on the Ostwald ripening process, involving solution-mediated polytypes and spiral-type transformations of mica $[18,21]$.

The elongation of lath-shaped illite is well known to be parallel to the $a$ axis direction $[16,17,29,30]$. It has naturally been supposed that the lath habit of illite would be produced by a preferential growth in the (100) direction. Fig. (5) shows the relation between the length or width and the thickness of Izumiyama hydrothermal illites, indicating the relative growth rates of the individual crystal surfaces. In the IZ-2 where lath-shaped illite particles were well formed, the ratio of the length to the thickness $(\mathrm{L} / \mathrm{T})$ of the lath-shaped particles was nearly equal to that of the platy particles (Fig. 5c). There was also no difference in the length or thickness between the lath-shaped and polygonal platy particles. Therefore, the growth rate in the length direction (100) was uniform within a certain range, regardless of the crystal morphology. In contrast, the ratio of the width to the thickness (W/T) of the lath-shaped particles was much lower than that of the platy particles (Fig 5d). These facts reflect that the lath habit of Izumiyama hydrothermal illites was produced by an inhibited growth in the width (010) direction instead of a preferential growth in the length (100) direction of the particles. Specifically, the formation of the lath habit was controlled by the growth rate in the $(010)$ direction of the parti- cles. It, however, is unclear what controlled the growth rate in the (010) direction of the illite particles.

On the other hand, in the IZ-1, there is a tendency that the ratio of the length or width to the thickness of the circular and polygonal platy $1 M$ illite particles is higher than that of the polygonal platy $2 M$ illite particles (Figs. 5a and b). The former seems to have grown more rapidly in the $a$ and $b$ axis directions and more slowly in the $c$ axis direction than the latter. Hirasawa and Uehara [20] has reported that these illite particles in the IZ-1 are divided into three types, based on their occurrence, morphology, and polytype: type 1 is euhedral $2 M$ illites growing in micropores of rocks, type 2 is subhedral $1 M$ illites occurring as inclusion of quartz crystal, and type 3 is subhedral to euhedral $1 M$ and $1 M_{d}$ illites in associated with quartz and K-feldspar. They also concluded that the type 1 illite was formed at higher temperature than those of type 2 and type 3 illites and that the formation order was type $2 \rightarrow$ type $1 \rightarrow$ type 3 . Judging from the morphology and polytype of the particles, the circular and polygonal platy $1 M$ illites identified by our AFM observation correspond to the type 2 or type 3 illite reported by Hirasawa and Uehara [20], and the polygonal platy $2 M$ illite corresponds to the type 1 illite. The type 1 illite was usually composed of many packets which are stacked in parallel to the $c^{*}$ direction, filling interstitial pore spaces, whereas the type 2 and type 3 illites tended to be thin, probably due to the limited space [20]. Therefore, the more rapid growth rate in the $c$ direction of the polygonal platy $2 M$ illite (type 1 ) than the circular and polygonal platy $1 M$ illite (type 2 and 3 ) was likely caused by relatively larger pore space for crystal growth as well as higher temperature.

\section{Polytype and Spiral Shape Transformation and Spiral Growth Mechanism}

In the IZ-2, there is a clear relation between particle morphology and spiral shape and mean step separation of illite particles (Table 2). Platy particles with circular spirals have narrower step separations than other particles. Polygonal platy and lath-shaped particles with interlacing patterns $\left(2 M_{1}\right.$ illite particles) tend to have wider step separations than other polygonal particles ( $1 \mathrm{M}$ and $2 O$ illite particles). This relation is also found in the IZ-1, although the relation is not apparent relative to that in the IZ-2 (Tables $\mathbf{1}$ and $\mathbf{2}$ ).

In general, polygonal steps having wider step separation are formed under lower supersaturation conditions than those of circular steps with narrower step separation $[6,8,15]$. The spiral growth rate of a particle having wider step separation is slower than that having narrower step separation because of the lower supersaturation conditions [31]. Therefore, particles having wider step separation should be thinner than those having narrower step separations.

In the sample IZ-2, however, illite particles with wider step separation tend to be thicker and longer than those having narrower step separation (Figs. 6d and e). As mentioned above, the particle dimension and step separation of circular $1 M$ illite particles with circular spiral patterns are the smallest and narrowest, respectively, in all the types. In addition, the particle dimension and step separation of the polygonal $2 M_{1}$ illite particles are larger and wider than those of other polygonal ( $1 M$ and $2 O$ ) particles. Therefore, the thickness 

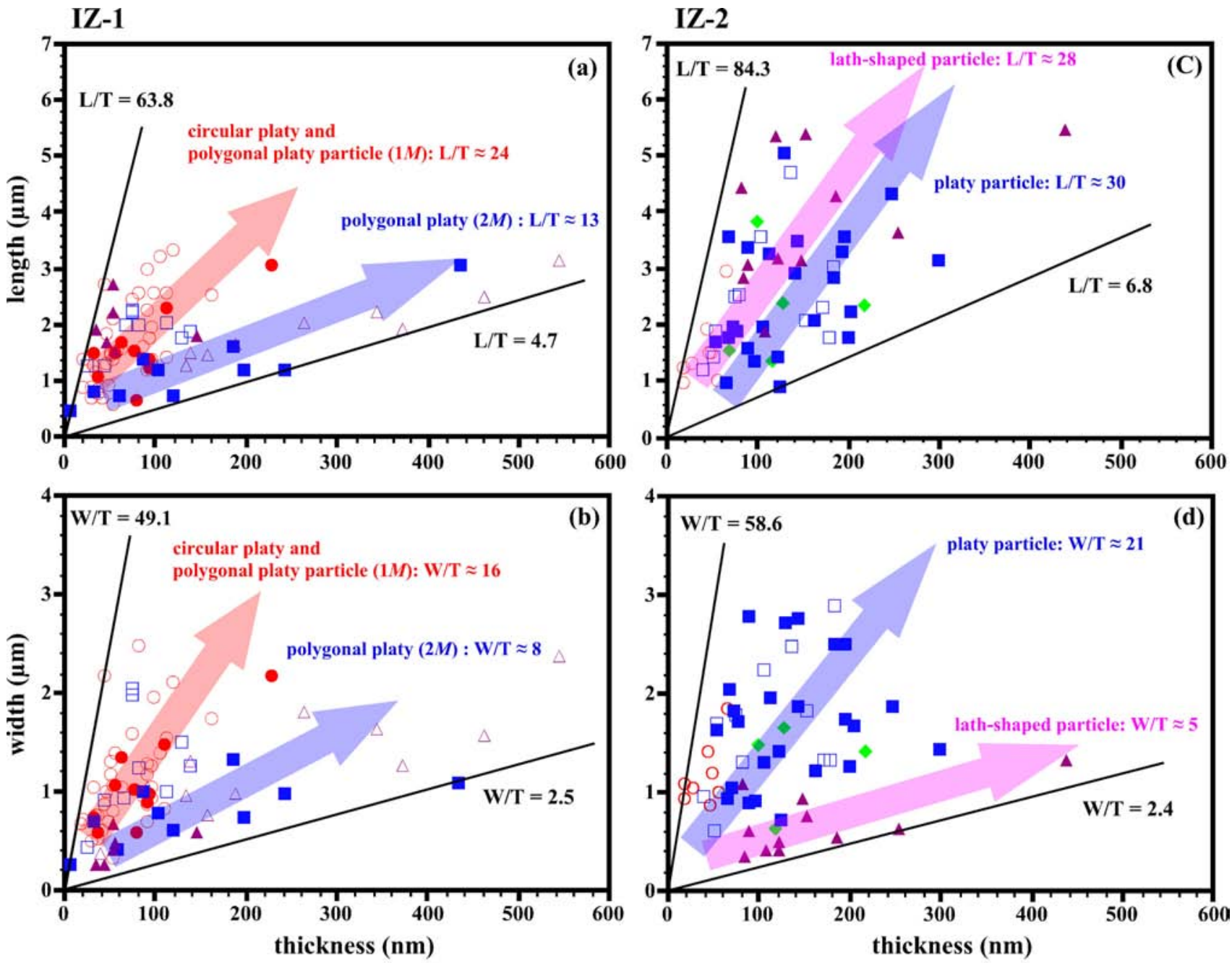

IZ-1 (a) and (b)

\begin{tabular}{|l}
\hline circular or malformed platy particle $(1 M)$ \\
circular or malformed platy particle $(2 M)$ \\
$\square$ polygonal platy particle $(1 M)$ \\
- polygonal platy particle $(2 M)$ \\
$\triangle \quad$ lath-shaped particle $(2 M,(1 M))$ \\
$\triangle$ kaolinite particle \\
\hline
\end{tabular}

IZ-2 (c) and (d)

\begin{tabular}{|ll|}
\hline & circular or malformed platy particle $(1 M)$ \\
$\square$ & polygonal platy particle $(1 M)$ \\
& polygonal platy particle $(2 O)$ \\
$\square$ & polygonal platy particle $(2 M)$ \\
$\triangle$ & lath-shaped particle $(2 M)$ \\
\hline
\end{tabular}

Fig. (5). Plots of length vs. thickness and width vs. thickness for individual illite and kaolinite particles in IZ-1 (a), (b) and IZ-2 (c), (d), respectively. Blue and pink arrows show trends of changes in particle dimensions of platy and lath-shaped particles, respectively. (after Kuwahara et al. [18])

and length of the particles seem to be proportionally related to the step separation, sequentially varying the morphology, spiral shape and polytype (i.e., circular $1 M \rightarrow$ polygonal platy $1 M$ and $2 O \rightarrow$ polygonal platy and lath-shaped $2 M_{1}$ ). The IZ-2 is a white clayey ore, which is composed of nearly pure illite, from illite veins of the inner, higher altered illite zone (Fig. 1). These illite particles must have been precipitated directly from hydrothermal solutions in open space (vein). In contrast, such variation is not apparent in the IZ-1 (Figs. 6a, b, and $\mathbf{c}$ ), although the step separation of circular platy particles tends to be narrower than those of polygonal platy and lath-shaped $2 M$ illite particles (Table 1). In the IZ1 three types of illites were likely formed under different temperature and pore space conditions, as described above.
The sequential variation observed especially in the IZ-2 is consistent with a speculative mechanism of solutionmediated polytype transformations for mica based on the Ostwald ripening process [21]. According to Baronnet [21], a large number of $1 M_{\mathrm{d}}$ particles first form during the initial nucleation stage. When supersaturation degree of the solution decreases, the particles smaller than the critical size will dissolve and form $1 M$ overgrowths on the larger $1 M_{\mathrm{d}}$ particles. Coalescence of particles could also take place along with the ripening, consequently producing the larger particles. As supersaturation degree decreases, the dissolving, smaller $1 M$ particles feed $2 M_{1}$ overgrowths on the larger $1 M$ particles. 

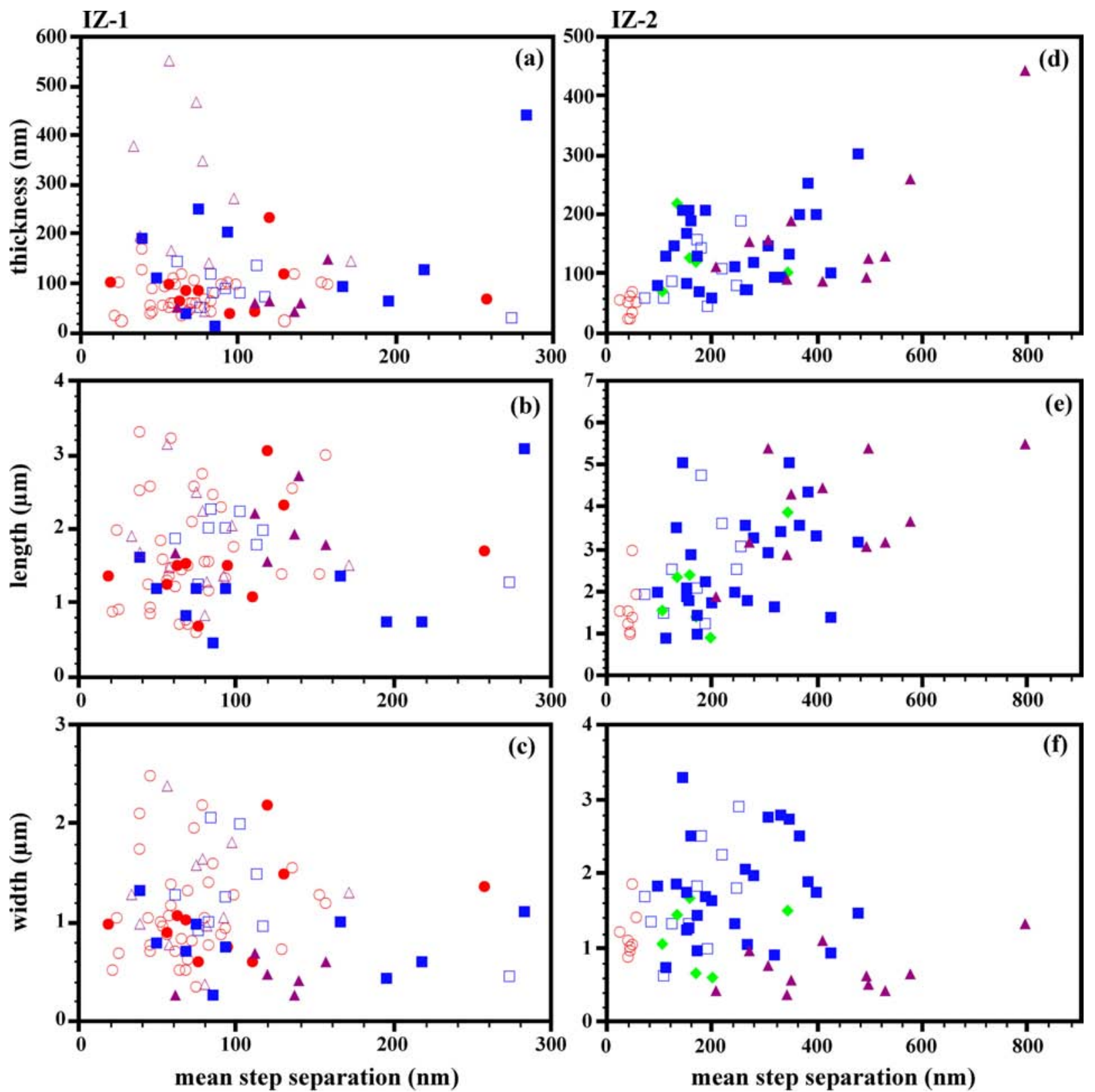

Fig. (6). Plots of thickness vs. mean step separation, length vs. mean step separation, and width vs. mean step separation for individual illite and kaolinite particles in IZ-1 (a), (b), (c) and IZ-2 (d), (e), (f), respectively. See Fig. (5) on each mark in this figure. (after Kuwahara et al. [18]).

For the Izumiyama illite, the platy $1 M$ illite particles with circular spirals were initially formed (probably after the initial stage of Baronnet [21]). Then the smaller particles dissolved, and $1 M$ and/or $2 O$ structures with polygonal spirals formed on the (001) surface of the larger $1 M$ particles having circular spirals. Finally, the $2 M_{1}$ illite crystallized on their surfaces. During the crystal growth and polytype transformation, the supersaturation of the hydrothermal solution probably decreased gradually. The particles exhibiting the $2 M_{1}$ structure, which was finally formed on the (001) surface, would be thicker than the other particles. In addition, our AFM study has revealed the coalescence of illite particles and overgrowth of illite layers (Fig. 7).

The deviation from equilibrium of a solution-precipitated illite particle can be estimated using step separation [15].
The step separation of a spiral $\left(r_{\text {step }}\right)$ is related to the critical radius of nucleation $\left(r_{c}\right)$, which is defined by the molar volume $(V)$, the surface energy $(\sigma)$, and the molar free energy of the dissolution reaction $\left(\Delta G_{d i s}\right)[15,32]$,

$$
r_{\text {step }} \approx 19 r_{c}=19 \mathrm{~V} \sigma / \Delta G_{\text {dis }}
$$

The mean step separations of five different types of Izumiyama illite in the IZ-1 and IZ-2 are listed in Tables $\mathbf{1}$ and 2 , respectively. Using these mean step separations, $\mathrm{V}=$ $140.31 \mathrm{~cm}^{3} / \mathrm{mol}$ for muscovite [33], and $\sigma=40.2 \mathrm{ergs} / \mathrm{cm}^{2}$ for illite [34], equation (1) estimates each $\Delta G_{d i s}$ for each mean step separation (Table 3). The saturation state of the solution can be estimated from the following equation,

$$
\Delta G_{d i s}=2.303 \mathrm{RT} \log (Q / K)(2),
$$


where $\mathrm{R}$ is the gas constant, $\mathrm{T}$ is the absolute temperature, $Q$ is the activity product of the solution, and $K$ is the equilibrium solubility product of illite. A $\log (Q / K)$ value $>0$ indicates increasing supersaturation while $<0$ indicates undersaturation.

The sample IZ-2 is nearly pure illite from illite veins of the inner, higher altered illite zone (Fig. 1) [19], and the temperature of hydrothermal alteration has been estimated to be $\sim 250^{\circ} \mathrm{C}[20,24]$. Hence, the hydrothermal solution is probably characterized by the illite $(0.88 \mathrm{~K})$ phase below the quartz saturation line $\left(\log \mathrm{a}_{\mathrm{H}_{4} \mathrm{SiO}_{4}}<-2.24\right)$ in Fig. 8) $[35,36]$. On the other hand, the sample IZ-1 is from the outer, weaker altered illite-kaolinite zone (Fig. 1) [19] and contains $1 M$ and $1 M_{d}$ illite (type 2 and type 3 ), $2 M$ illite (type 1 ), kaolinite,
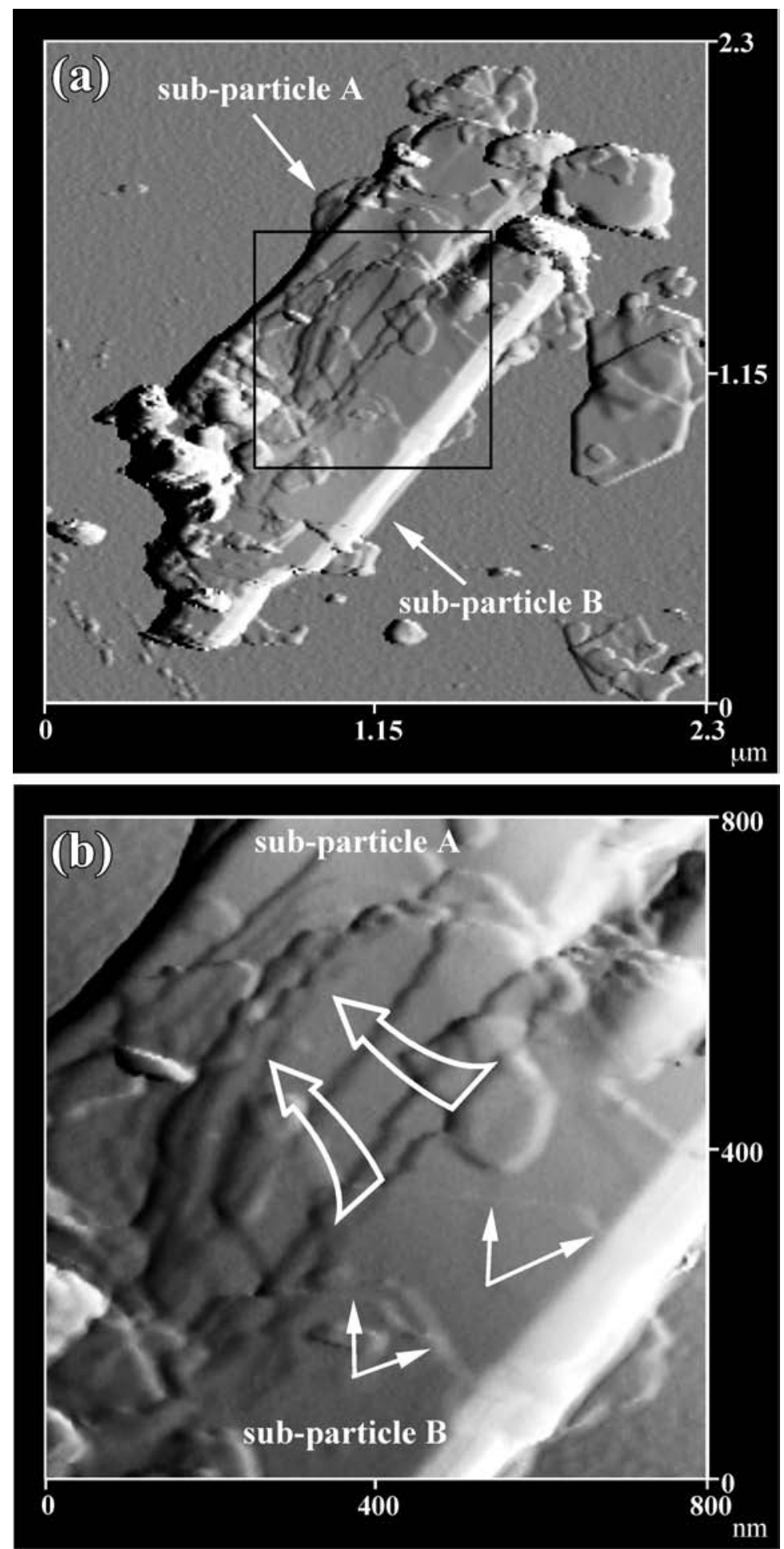

Fig. (7). (a) TMAFM amplitude image showing an illite particle into which two lath-shaped particles (sub-particles A and B) coalesced. (b) Magnified view within the box in (a). Open arrows show that the illite layers of sub-particle B overgrow on the surface of sub-particle A. Solid arrows show polygonal steps on the surface of sub-particle B. 

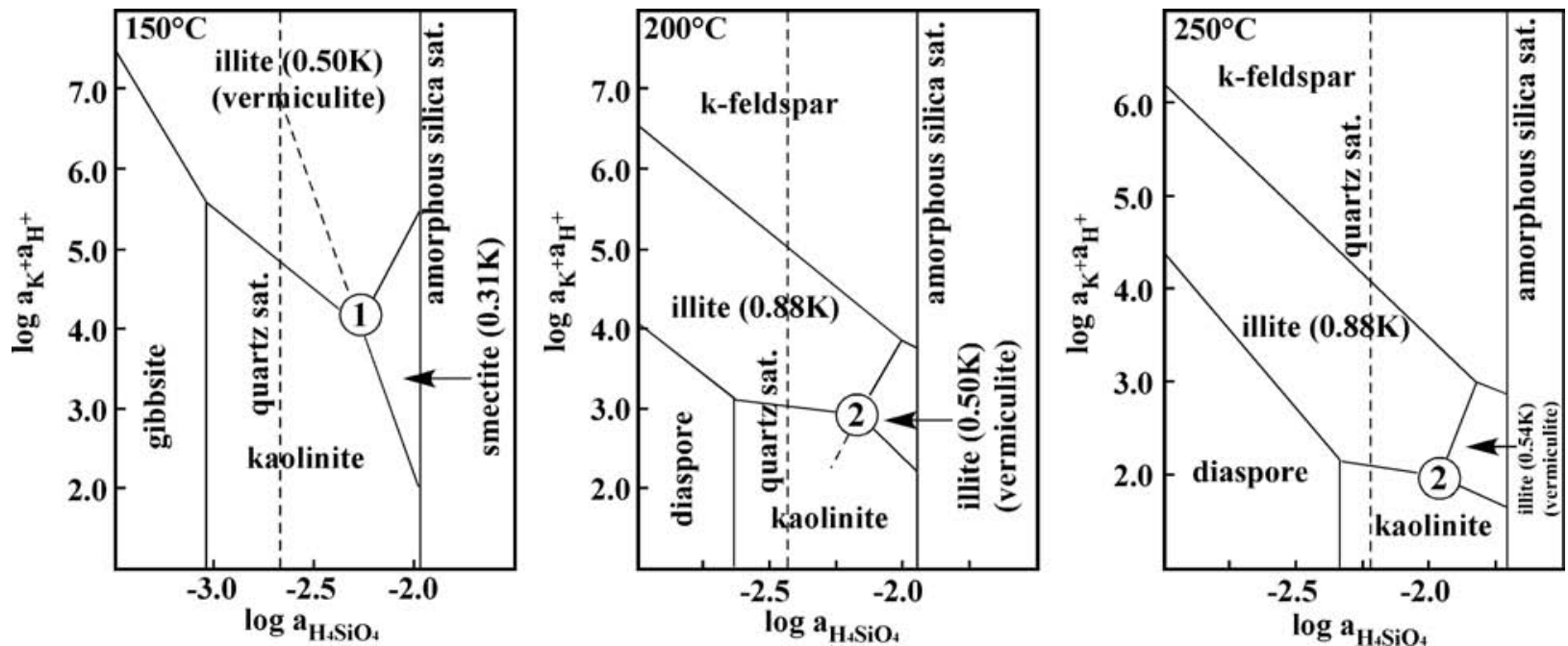

Fig. (8). Isothermal, isobaric phase diagram from Yates and Rosenberg [36] showing the stability fields of illite, I-S, and smectite at $150^{\circ} \mathrm{C}$, $200^{\circ} \mathrm{C}$ and $250^{\circ} \mathrm{C}$. Metastable phase boundaries are indicated by stippled lines. Invariant points of different smectite composition are indicated by numbers 1 and 2 .

K-feldspar and quartz [20]. As mentioned above, the type 1 illite formed at higher temperature than the type 2 and the type 3 illites and the order of formation was type $2 \rightarrow$ type 1 $\rightarrow$ type 3 [20]. The type 2 illite occurred as inclusions of quartz crystals, whereas the type 1 illite grew in contact with quartz or K-feldspar in micropores of rocks. Our AFM observation of the IZ-1 newly provides evidence that $2 M$ illite layers overgrew on the surface of kaolinite particle (Fig. 9). Based on these facts and the phase diagram in Fig. (8), the temperature of the hydrothermal solution may vary at least from about $150^{\circ} \mathrm{C}\left(1 M\right.$ and $1 M_{d}$ illite, kaolinite and quartz) to $200^{\circ} \mathrm{C}$ ( $2 M$ illite, $\mathrm{K}$-feldspar and quartz), and finally decrease below $150^{\circ} \mathrm{C}\left(1 M_{d}\right.$ illite, kaolinite and quartz).

We estimated the $\log (Q / K)$ values at temperatures of $200^{\circ} \mathrm{C}$ for the IZ-1 and $250^{\circ} \mathrm{C}$ for the IZ-2 (Table 3). The particles having circular spirals formed under relatively high supersaturation conditions. In contrast, the $2 M$ structure on the polygonal platy or lath-shaped particles grew very slowly under nearly equilibrium solution conditions. In the IZ-1, the $2 M$ structure could form under solution conditions with log $(Q / K)<0.1$. On the other hand, this in the IZ-2 seems to oc- cur mainly at lower $\log (Q / K)$ value. However, the $2 M$ structure in the IZ-2 could practically form under the same conditions as in the IZ-1, since the narrowest step separation of the $2 M$ illite particles is about $100 \mathrm{~nm}$ corresponding to $\log$ $(Q / K) \approx 0.1$. Fig. (10) illustrates the paths of the thermal and supersaturation conditions of the Izumiyama hydrothermal solutions. In the IZ-1, the illite particles having circular spirals and/or polygonal single layer spiral $(1 M)$ (and kaolinite particles (Fig. 7)) were initially formed as the increase of temperature $\left(\sim 150^{\circ} \mathrm{C}\right.$ to $\left.200^{\circ} \mathrm{C}\right)$ and the decrease in supersaturation condition of the solution. When the supersaturation condition, $\log (Q / K)$, decreased below about 0.1 and the temperature reached $200^{\circ} \mathrm{C}$, the $2 \mathrm{M}$ illite particles or structures would produce. Finally, the illite particles having circular spirals and/or polygonal single layer spirals $(1 M)$ then formed as the increase in supersaturation condition of the solution following the decrease in temperature. On the other hand, in the IZ-2, the supersaturation of the solution decreased gradually during the polytype transformation of a spiral shape ( $1 M$ circular spirals $\rightarrow 1 M, 2 O$ polygonal spirals $\rightarrow 2 M_{1}$ polygonal spirals), at higher temperature $\left(\sim 250^{\circ} \mathrm{C}\right)$.

Table 3. Deviation from Equilibrium of a Solution-Precipitated Illite Particle Estimated from Mean Step Separations of Hydrothermal Illites in the IZ-1 and IZ-2

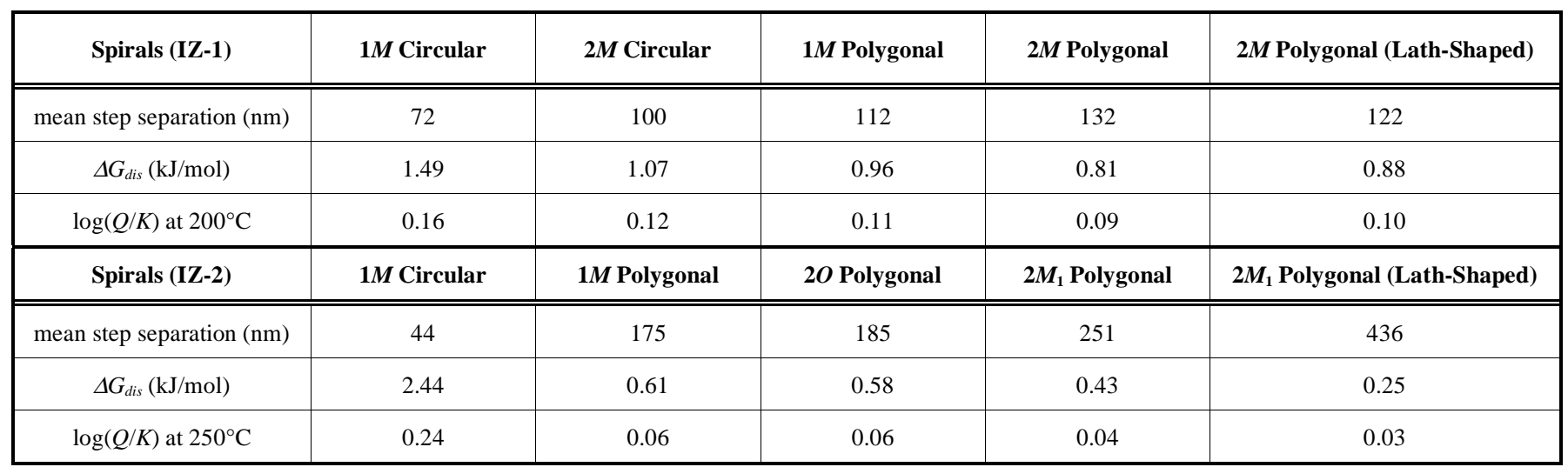



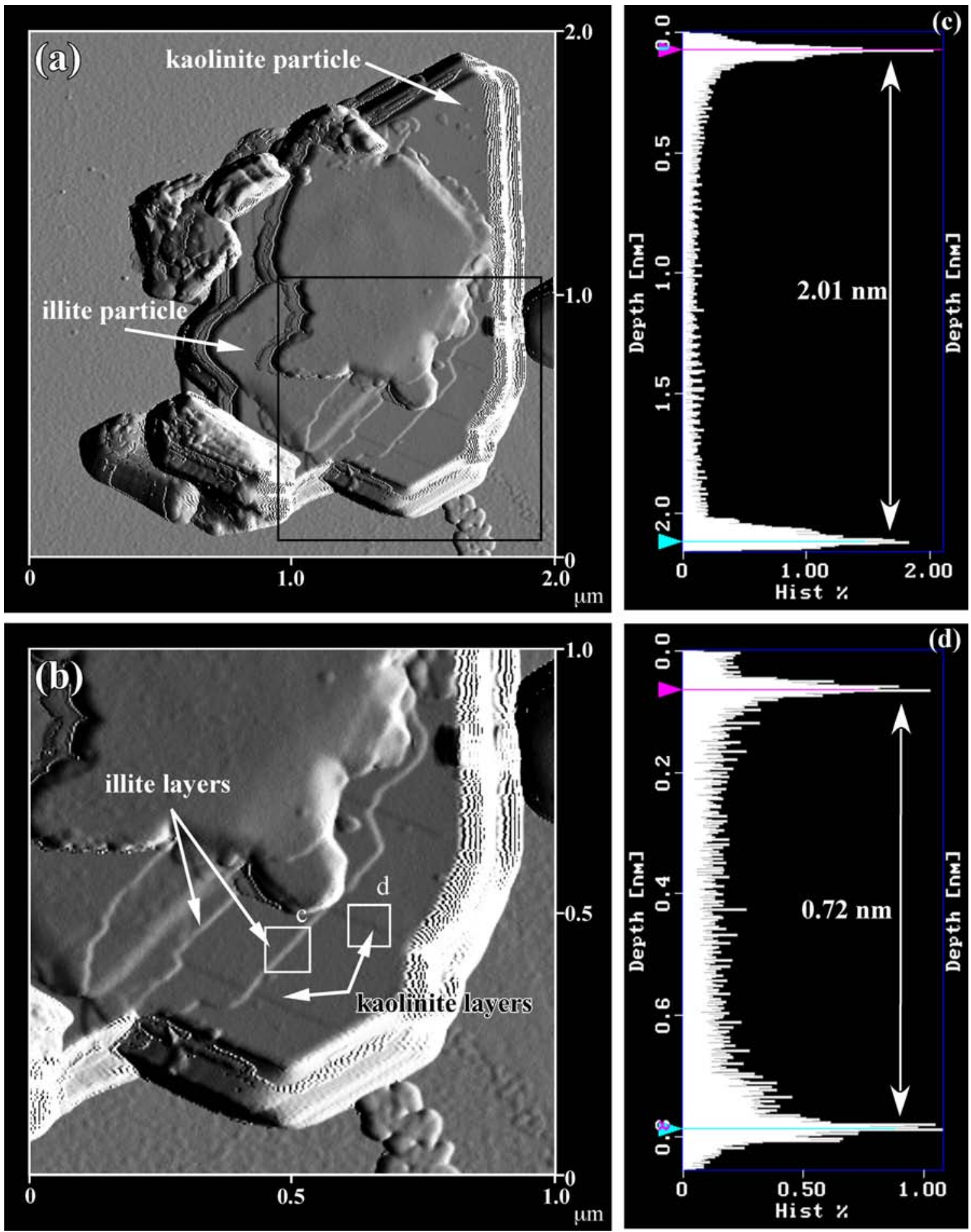

Fig. (9). TMAFM amplitude image of illite particle overgrowing on the surface of kaolinite particle (IZ-1). (b) Magnified view within the box in (a). (c) Height histogram of the data points within the box c in (b). The step in the box c has a height of $2.01 \mathrm{~nm}$ corresponding to the thickness of two single unit-cell layers of mica. (d) Height histogram of the data points within the box $d$ in (b). The step in the box $d$ has a height of $0.72 \mathrm{~nm}$ corresponding to the thickness of a 1:1 layer of kaolinite.

\section{CONCLUSIONS}

This study demonstrated that the Izumiyama hydrothermal illite particles formed as the result of a mechanism involving solution-mediated polytypes and spiral-type transformation, based on the Ostwald ripening process. The initially formed smaller particles would dissolve and form different polytype structures on the larger particles. Coales- cence of particles also took place along with the ripening, and consequently produced the larger particles. The overgrowths of illite layers occurred on the surface of not only illite but also kaolinite. The supersaturation conditions of the hydrothermal solutions for the two different occurrences changed along different paths, resulting in the overgrowth and polytype transformation. 


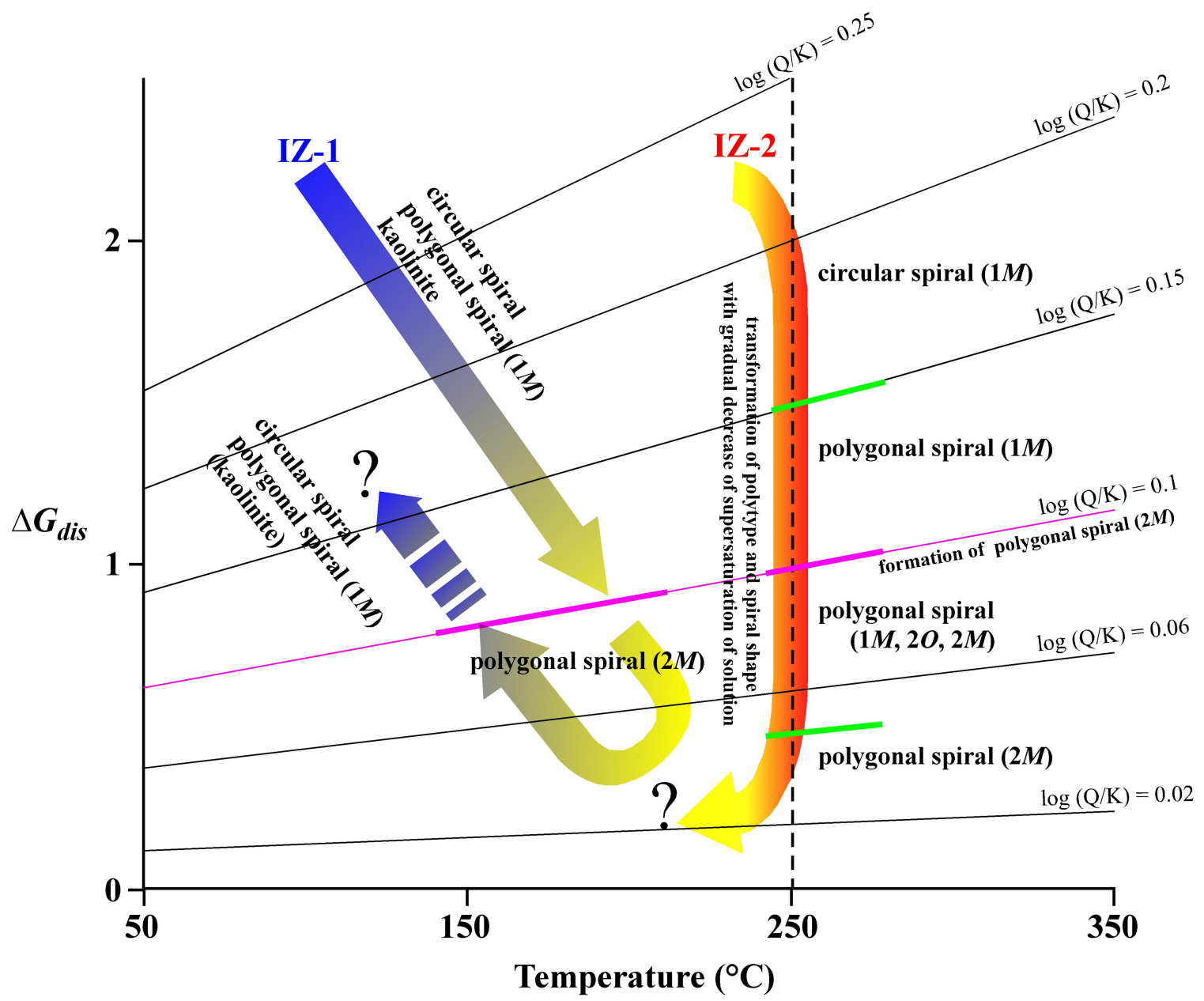

Fig. (10). Thermal and supersaturation conditions of the Izumiyama hydrothermal solutions during crystal growth and polytype transformation of illites estimated from this AFM study.

\section{ACKNOWLEDGEMENTS}

We are grateful to K. Ishida and Y. Nakamuta of Kyushu University for many discussions and helpful suggestions. The authors thank four anonymous reviewers for helpful and constructive reviews. This study was supported in part by the Grant-in-Aid for Scientific Research (Y. Kuwahara, No. 17540457) from the Japan Society for the Promotion of Science.

\section{REFERENCES}

[1] Frank, E.C. The influence of dislocations on crystal growth. Discus. Faraday Soc., 1949, 5, 48-54.

[2] Sunagawa, I. Step height of spirals on natural hematite crystals. Am. Mineral., 1961, 46, 1216-1226.

[3] Sunagawa, I. Growth spirals on phlogopite crystals; Am. Mineral., 1964, 49, 1427-1434.

[4] Komatsu, H.; Sunagawa, I. Surface structures of sphalerite crystals. Am. Mineral., 1965, 50, 1046-1057.

[5] Gritsaenko, G.S.; Samotoyin, N.D. In the decoration method applied to the study of clay minerals, Proceedings of the International Clay Conference, Jerusalem, Israel. Heller, L.; Weiss, A. Eds.; Israel Program for Scientific Translations, 1966; Vol 3; pp. 391.

[6] Sunagawa, I.; Koshino, Y. Growth Spirals on Kaolin Group Minerals. Am. Mineral., 1975, 60, 407-412.

[7] Tomura, S.; Kitamura, M.; Sunagawa, I. Surface microtopography of metamorphic white micas. Phys. Chem. Miner., 1979, 5, 65-81.

[8] Kitagawa, R; Takeno, S.; Sunagawa, I. Surface microtopographies of sericite crystals formed in different environmental conditions. Mineral. J., 1983, 11, 282-296.
[9] Kitagawa, R. Surface microtopography of illite crystals from different modes of occurrence. Can. Mineral., 1998, 36, 1559-1567.

[10] Baronnet, A. Growth mechanisms and polytypism in synthetic hydroxyl-bearing phlogopite. Am. Mineral., 1972, 57, 1272-1293.

[11] Jige, M.; Kitagawa, R.; Zaykov, V.V. Surface microtopography of sudoite. Clay Miner., 2003, 38, 375-382.

[12] Lindgreen, H.; Granæs, J.; Hansen, P.L.; Besenbacher, F.; Lægsgaard, E.; Stensgaard, I.; Gould, S.A.C.; Hansma, P.K. Ultrafine Particles of North Sea Illite/Smectite Clay Minerals Investigated by STM and AFM. Am. Mineral., 1991, 76, 1218-1222.

[13] Nadeau, P.H.; Wilson, M.J.; McHardy, W.J.; Tait, J.M. Fundamental nature of illite/smectite. Clays Clay Miner., 1987, 35, 77-79.

[14] Lindgreen, H.; Granæs, J.; Besenbacher, F.; Lægsgaard, E.; Stensgaard, I. Illite-smectite from the north sea investigated by scanning tunnelling microscopy. Clay Miner., 1992, 27, 331-342.

[15] Blum, A.E. Scanning Probe Microscopy of Clay Minerals, CMS Workshop Lectures, 7; Nagy, K.L.; Blum, A.E. Eds.; The Clay Minerals Society: Bloomington, Indiana. 1994; pp. 172-202.

[16] Nagy, K.L. Scanning Probe Microscopy of Clay Minerals, CMS Workshop Lectures, 7; Nagy, K.L.; Blum, A.E. Eds.; The Clay Minerals Society: Bloomington, Indiana. 1994; pp. 204-239.

[17] Kuwahara, Y.; Uehara, S.; Aoki, Y. Surface Microtopography of lath-shaped hydrothermal illite by Tapping-Mode ${ }^{\mathrm{TM}}$ and contactMode AFM. Clays Clay Miner., 1998, 46, 547-582.

[18] Kuwahara, Y.; Uehara, S.; Aoki, Y. Atomic force microscopy study of hydrothermal illite in izumiyama pottery stone from arita, saga prefecture, Japan. Clays Clay Miner., 2001, 49, 300-309.

[19] Nakagawa, M.; Nakamoto, J.; Yoshihara T. Hydrothermal alteration at the Izymiyama pottery stone deposit, Saga Prefecture - mineralogical properties of quartz and $\mathrm{NH}_{4}$-bearing sericite. Nendo Kagaku (J. Clay Sci. Soc. Jpn.), 1995, 35, 1-14. 
[20] Hirasawa, K.; Uehara, S. Hydrothermal history of the Izumiyama pottery stone deposit. Resource Geol., 1999, Special Issue 20, 113122.

[21] Baronnet, A. Minerals and Reaction at the Atomic Scale: Transmission Electron Microscopy, Reviews in Mineralogy, 27; Buseck, P.R. Ed.; Mineralogical Society of America: Washington, D.C. 1992; pp. 231-288.

[22] Inoue, A; Kohyama, N.; Kitagawa, R.; Watanabe, T. Chemical and morphological evidence for the conversion of smectite to illite. Clays Clay Miner., 1987, 35, 111-120.

[23] Inoue, A.; Velde, B.; Meunier, A.; Touchard, G. Mechanism of illite formation during smectite-to-illite conversion in a hydrothermal system. Am. Mineral., 1988, 73, 1325-1334.

[24] Maeda, K.; Watanabe, K.; Izawa, E.; Itaya, T.; Takeuchi, K. K-Ar ages of gold mineralization and argillization in the Arita-Hasami area, Western Kyushu, Japan. Resour. Geol., 1996, 46, 25-31 (in Japanese).

[25] Barrett, S.D. Image analysis and the internet. Sci. Data Manag., 1997, $1,18$.

[26] Bickmore, B.R.; Rufe, E.; Barrett, S.D.; Hochella, M.F. Jr. Measuring Discrete Feature Dimensions in AFM Images with Image SXM. Geol. Mater. Res., 1999,1, 1.

[27] Środoń, J; Eberl, D.D. 1984 Illite. Micas, Reviews in Mineralogy, 13; Bailey, S.W. Ed.; Mineralogical Society of America: Washington, D.C., 1984, 495-544.

[28] Griffen, D.T. Silicate Crystal Chemistry; Griffen, D.T. Ed.; Oxford University Press: New York. 1992, 101-149.
[29] McHardy, W.J.; Wilson, M.J.; Tait, J.M. Electron microscope and $\mathrm{X}$-ray diffraction studies of filamentous illitic clay from sandstones of the Magnus Field. Clay Miner., 1982, 17, 23-39.

[30] Kantorowicz, J.D. The influence of variations in illite morphology on the permeability of middle Jurassic Brent group sandstones. Cormorant Field, UK North Sea: Mar. Petrol. Geol., 1990, 7, 6674.

[31] Kuroda, T. Kesshou-ha-ikiteiru (Crystal lives): The Mechanism of its Growth and Transformation of Morphology, Saiennsu-sha: Tokyo, 1984 (in Japanese).

[32] Blum, A.E.; Lasaga, A.C. Aquatic Surface Chemistry: Chemical Processes at the Particle-Water Interface, Stumm, W. Ed.; John Wiley \& Sons: New York, 1987; pp. 255-292.

[33] Robie, R.A.; Hemingway, B.S.; Fisher, J.R. Thermodynamic properties of minerals and related substances at $298.15 \mathrm{~K}$ and $1 \mathrm{Bar}$ pressure and at higher temperatures. U.S. Geol. Survey Bull., 1978 , $1452,456 \mathrm{c}$.

[34] Giese, R.F.; van Oss, C.J. Health Effects of Mineral Dusts, Reviews in Mineralogy, 28; Guthrie, G.D.; Mossman, B.T. Eds.; Mineralogical Society of America: Washington, D.C. 1993; pp. 327-346

[35] Yates, D.M.; Rosenberg, P.E. End-member illite: An ordered domain. structure? Geochim. Cosmochim. Acta, 1999, 61, 3135-3144.

[36] Meunier, A.; Velde, B. Illite. Origins, Evolution and Metamorphism. Springer-Verlag: Berlin Heidelberg, 2004.

(C) Kuwahara and Uehara; Licensee Bentham Open.

This is an open access article licensed under the terms of the Creative Commons Attribution Non-Commercial License (http://creativecommons.org/licenses/ by-nc/3.0/) which permits unrestricted, non-commercial use, distribution and reproduction in any medium, provided the work is properly cited. 